\title{
A study of tropical eosinophilia
}

\author{
FAROKH E. UDWADIA AND V. V. JOSHI \\ From the J. J. Hospital, Bombay, India
}

The aetiopathology of tropical eosinophilia presents a baffling problem in spite of a great deal of work on this subject in the last four years. The natural history of any disease rests on a good understanding of its pathology, and so far there have not been many pathological observations on the lung in this condition, possibly because of its apparently benign nature. This paper records the investigation of 26 patients with tropical eosinophilia who underwent a full clinical, radiological, and pathological study. All had open lung biopsies: 24 were taken prior to specific treatment, and two after a month's treatment with diethylcarbamazine.

\section{MATERIAL AND METHODS}

The selection of patients for this study was based on clinical features and haematological findings. Paroxysmal nocturnal cough and breathlessness, with a peripheral eosinophilia of at least $3,500 / \mathrm{c} . \mathrm{mm}$., were present in 25 out of 26 patients. The remaining patient presented with a high peripheral eosinophilia: total leucocytes $18,000 /$ c.mm. with $60 \%$ eosinophils. He had no symptoms or signs, and no cause for the eosinophilia could be found on routine clinical and laboratory investigation. Twenty-four of our 26 patients were first studied clinically, haematologically, and radiologically. This took about one week, during which no specific therapy was given, and they were then subjected to an open lung biopsy. This was done under general anaesthesia by a thoracic surgeon; the thoracic cavity was opened through a $3-i n .(7 \cdot 62-\mathrm{cm}$.) incision and a small wedge of lung tissue measuring about $2 \times 1$ to $1 \frac{1}{2}$ in. $(5.08 \times 2.54$ to $3.81 \mathrm{~cm}$. $)$ was removed. The procedure took about 20 to 30 minutes. The patient was ambulant in 24 hours and the wound healed in seven days. Diethylcarbamazine was started the day after the biopsy in a dose of $100 \mathrm{mg}$. four times a day, and this was continued for at least one month. One of the 24 patients (patient K.S.) was unusual, and it was decided to follow him for six weeks after biopsy before starting him on specific therapy.

Two of the 26 patients had a full course of diethylcarbamazine for one month and each was submitted to an open lung biopsy.

Total and differential white blood cell counts of all the above patients were done weekly for the first two months and then once every two weeks for the next six months. A further follow-up of every patient was maintained for as long as possible, the maximum period for some patients being for over two years.

The biopsy material was fixed and sectioned into as many sections (usually about 200 ) as feasible, the thickness of each being $5 \mu$ to $7 \mu$ : all these were stained and examined.

\section{RESULTS}

Parasites were detected in the lung in three of the 26 biopsies.

The following histopathological reactions were observed in the lung during a study of the numerous lung sections:

I Acute eosinophilic infiltration, 'eosinophilic bronchopneumonia', and eosinophilic abscesses'

II Histiocytic infiltration

III Mixed cell type of infiltrate (i.e., eosinophils and histiocytes) with generally well-marked fibrous tissue formation.

ACUTE EOSINOPHILIC INFILTRATION WITH THE FORMATION OF 'EOSINOPHILIC ABSCESSES'; 'EOSINOPHILIC BRONCHOPNEUMONIA' (Fig. 1) The lesions were in the main peribronchial and perivascular and consisted of dense accumulations of eosinophils ; at many such places the alveolar walls had disintegrated and the lung architecture was distorted. Granulomatous areas with necrotic material were seen in some sections; giant cells mostly of the foreign body type were also observed. There was an increased vascularity of the acute lesions, a dilatation of the lymphatics, and a fibrinous exudate was also found.

Perivascular cuffing with eosinophils was seen, and they also infiltrated the interstitial tissue, which became quite thick.

Bronchioles showed infiltration with eosinophils ; oedema of the wall was seen and the musculature was occasionally disrupted. The mucous membrane was often shed free in the bronchial lumen, which could be blocked by clumps of eosinophils. 


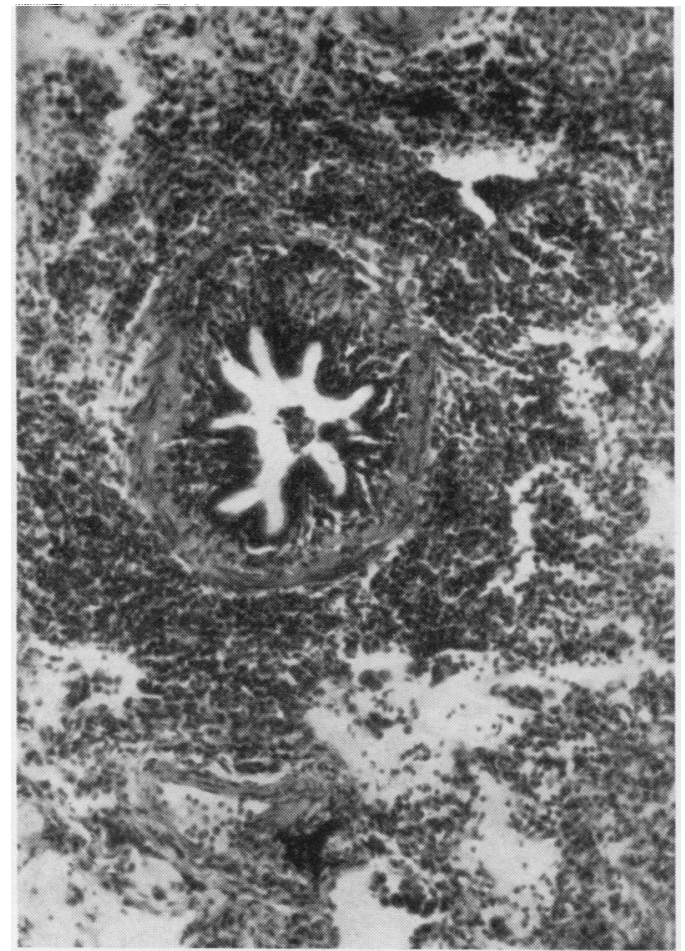

cIG. 1. Acute eosinophilic infiltration; eosinophilic bronchopneumonia. $H$. and $E ., \times 156$.

A few vessels seemed obliterated.

Fibrous tissue proliferation was occasionally associated with the acute lesions.

HISTIOCYTIC INFILTRATION OF THE LUNG PARENCHYMA The three patients with the shortest duration of symptoms (less than three weeks) before biopsy all presented an unusual histology. There were very few eosinophils in the infiltrate; an interstitial, peribronchial, and perivascular exudate consisting of histiocytes was present. Clumps of histiocytes were also found in many alveolar spaces. At some sites the abovementioned cells were all clustered densely to form a granulomatous area in which the lung parenchyma was destroyed. Of these three early patients K.S. was unique, for microfilaria were identified in the peripheral blood and also in the lung (Fig. 2). These microfilaria closely resembled Microfilaria malayi but they could well have been animal filaria. A clinical description and discussion of this patient forms the subject-matter of another paper.

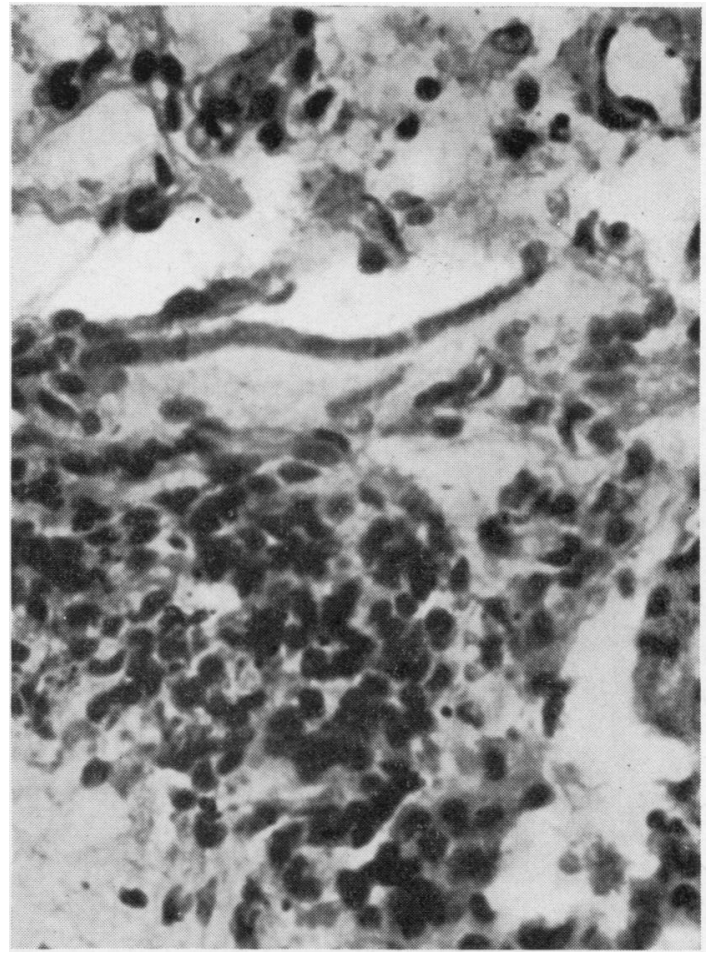

FIG. 2. Microfilaria in the lung with histiocytic infiltration of the lung parenchyma. H. ani $E ., \times 500$.

In a few patients the histiocytic infiltration was very dense, and in one there was a capsulated basophilic subpleural mass (Fig. 3). This was undoubtedly a parasite, but its exact nature was impossible to identify in the presence of so much calcification. Another showed the presence of a parasitic body whose exact nature could not be determined.

Sometimes, as in the patient presenting with only peripheral eosinophilia and in another (patient N. A.) in whom the duration of symptoms was 12 years, the lesions took an indolent form with histiocytes, lymphocytes, and fibrous tissue (Figs. 4 and 5).

'MIXED-CELL TYPE' WITH GENERALLY WELL-MARKED FIBROUS TISSUE FORMATION (Fig. 6) EOsinophilic lesions were associated with histiocytic and lymphocytic infiltration of the interstitial tissue; much fibrosis was usually evident.

Fibrous tissue formation occurred quite early in the course of the natural history. This fibrosis was initially interstitial and was also peribronchial 


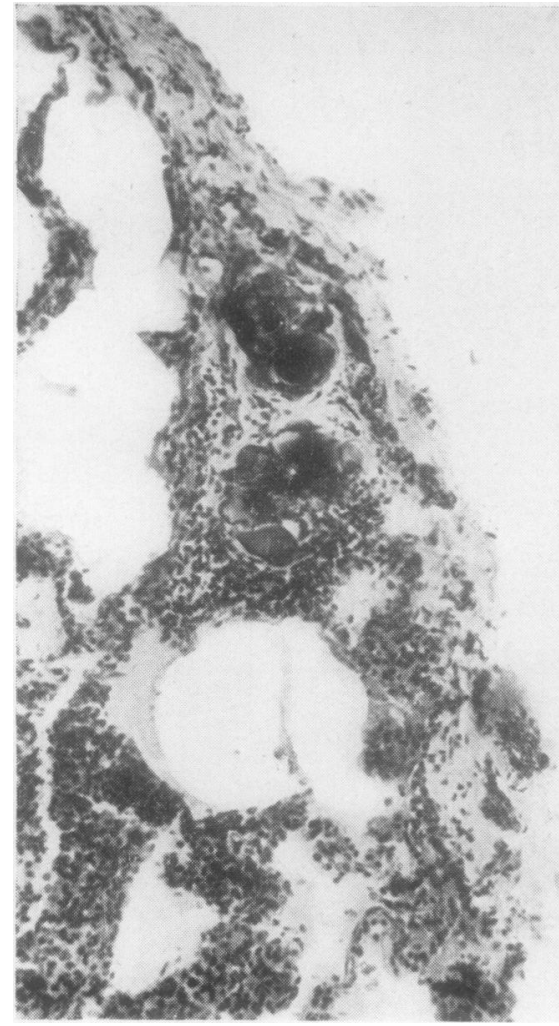

FIG. 3. Subpleural capsulated basophilic mass-a parasite the nature of which could not be detected. $H$. ard $E$., $\times 156$.

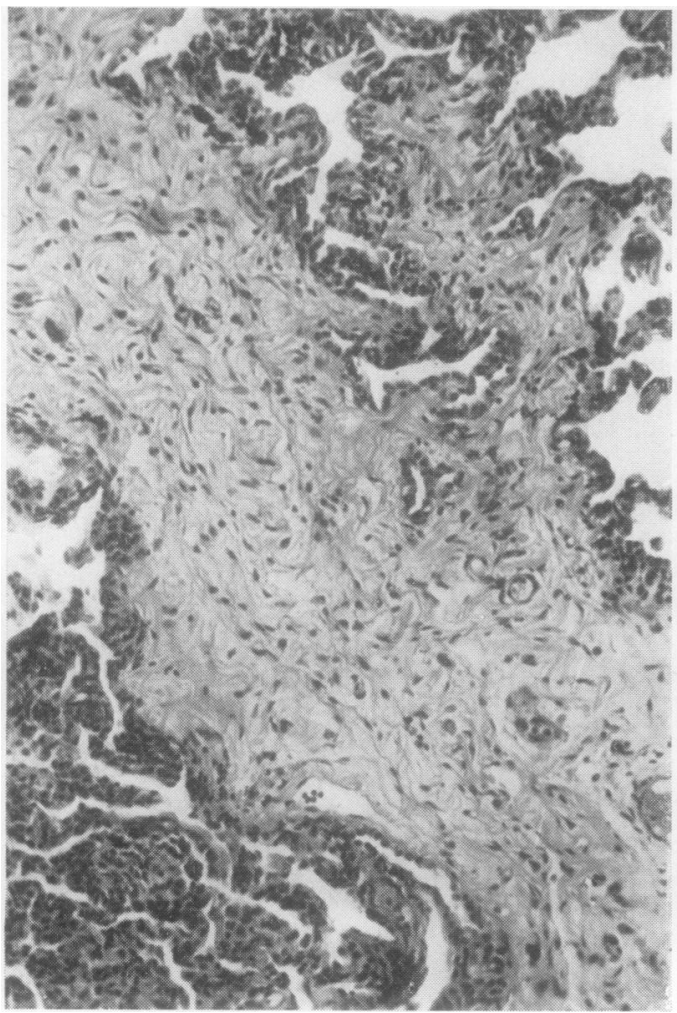

FIG. 5. Chronic histiocytic and lymphocytic infiltration with well-marked pulmonary fibrosis. $H$. cnd $E ., \times 156$.

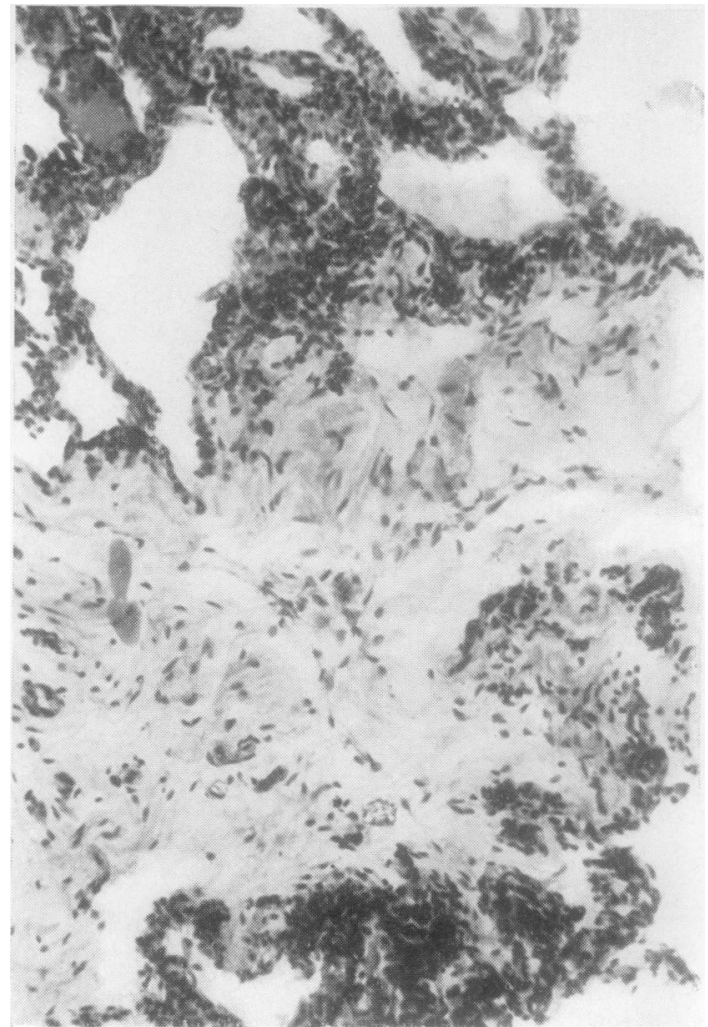

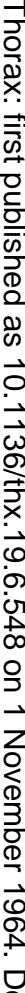

FIG. 4. Case presenting solely with a marked peripheral eosinophilia. Note chronic histiocytic and lymphocytic infiltration with fibrosis. $H$. and $E ., \times 156$.

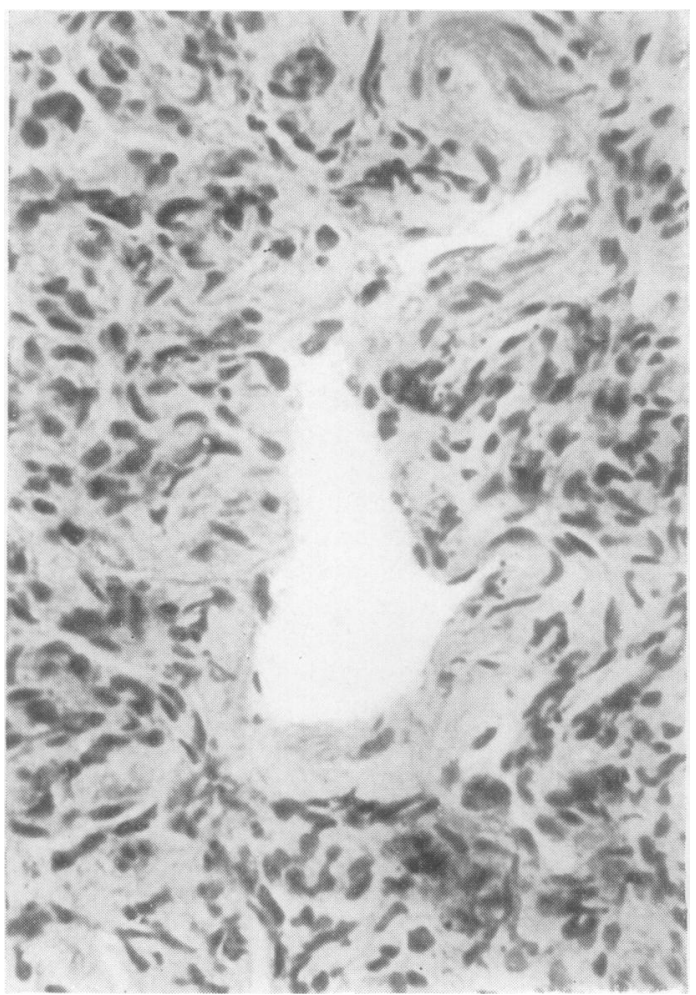

FIG. 6. 'Mixed-cell type' of lesion. Eosinophils and histiocytes with well-marked pulmonary fibrosis. $H$. and $E$., 500. 
and perivascular. The latter distribution was seen even in early acute eosinophilic lesions. This was easily explained, as the acute pathology involved the peribronchial and perivascular lung tissue; destruction of such lung tissue was followed by a replacement fibrosis. As the fibrosis progressed dense fibrous bands connected the bronchioles and the vessels. There was also much pleural thickening and fibrous bands starting from the subpleural fibrous tissue dipped down into the lung parenchyma, often linking up with the peribronchial and perivascular tissue. The lung parenchyma then appeared artificially compartmentalized by these fibrous bands (Fig. 7). It is a noteworthy feature that though disruption of the alveolar walls was seen in places the overall picture was not of any significant emphysema but of pulmonary fibrosis. The histopathology in the lung was best summarized as a 'restrictive pathology' ; this holds true for the early and late lesions of tropical eosinophilia.

The Table gives the type of histopathological reaction observed in relation to the duration of symptoms before hospitalization.

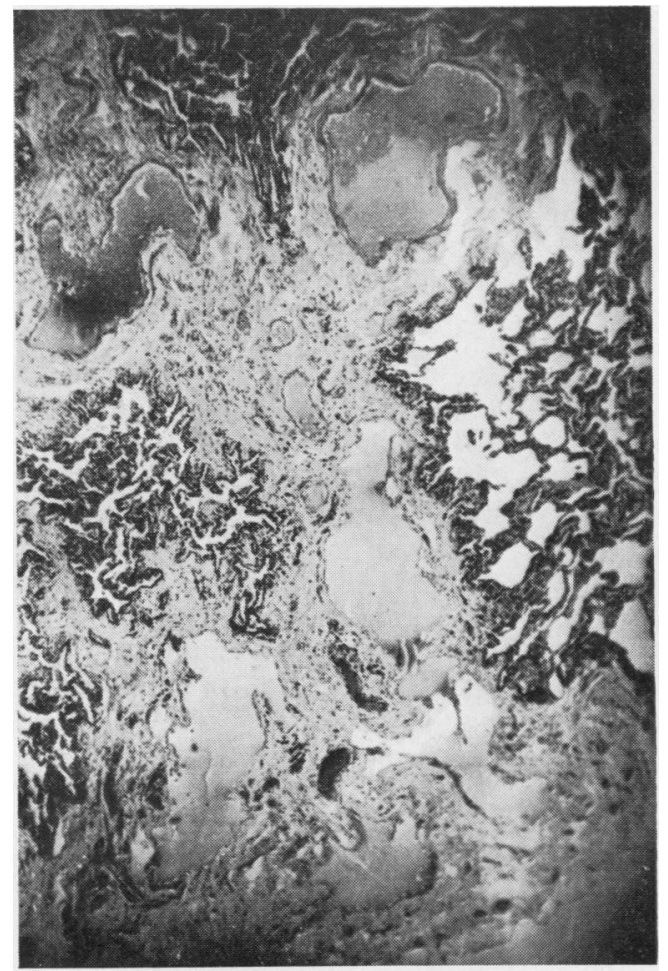

FIG. 7. Well-marked pulmonary fibrosis-an end result of long standing untreated tropical eosinophilia. H. and E., $\times 44$.
TABLE

\begin{tabular}{|c|c|c|}
\hline $\begin{array}{l}\text { Duration of } \\
\text { Symptoms }\end{array}$ & $\begin{array}{l}\text { No. of } \\
\text { Patients }\end{array}$ & Histology \\
\hline Less than 2 weeks & 3 & $\begin{array}{l}\text { Histiocytic infiltration in all ; } \\
\text { typically the same reaction in } \\
\text { each. }\end{array}$ \\
\hline $1-3 \mathrm{mth}$. & 4 & $\begin{array}{l}\text { Three showed acute eosinophiiic } \\
\text { lesions ; one showed a 'mixed } \\
\text { cell type' reaction. }\end{array}$ \\
\hline $6 \mathrm{mth} .-1 \mathrm{yr}$. & 7 & $\begin{array}{l}\text { Five showed a mixed reaction ; } \\
\text { well-marked fibrosis in all. } \\
\text { Two showed acute eosinophilic } \\
\text { lesions with fibrosis }\end{array}$ \\
\hline Approx. 2-3 yr. & 7 & $\begin{array}{l}\text { Two showed a predominant } \\
\text { histiocytic response ; five } \\
\text { showed a mixed-cell type of } \\
\text { response; well-marked fibrosis } \\
\text { in all. }\end{array}$ \\
\hline More than $10 \mathrm{yr}$. & 2 & $\begin{array}{l}\text { (a) } 11 \text { years' history : all grades } \\
\text { of lesions and all types of cells } \\
\text { with well-marked fibrosis. } \\
\text { (b) } 12 \text { years' histoly : chronic } \\
\text { indolent lesion with histiocytic } \\
\text { infiltration and fibrosis }\end{array}$ \\
\hline $\begin{array}{l}\text { No symptoms, presen- } \\
\text { ted as a peripheral } \\
\text { eosinophilia of un- } \\
\text { known aetiology }\end{array}$ & 1 & $\begin{array}{l}\text { Chronic indolent histiocytic in- } \\
\text { filtration with well-marked } \\
\text { fibrosis }\end{array}$ \\
\hline
\end{tabular}

The histopathological features of the two patients submitted to biopsy after one month's treatment with diethylcarbamazine are dealt with in the discussion.

\section{DISCUSSION}

Few pathological observations have been made in cases of tropical eosinophilia. They are based on the initial description by Viswanathan (1947, 1948) and subsequently by others (Beaver and Danaraj, 1958 ; Chaudhuri, 1956 A ; Chaudhuri, Aikat, and Sanjivi, 1954 ; Chaudhuri and Saha, 1959; Chaudhuri and Saha, 1961; D'Abrera, 1958 ; Gault and Webb, 1957). Webb, Job, and Gault (1960) described the lung histology in two cases ; Chaudhuri and Saha (1961) described the histology in one case. These accounts leave many questions unanswered. What is the earliest histopathological change in the lung in this syndrome? What is its natural history? What happens to the lung when tropical eosinophilia is left untreated for many years? Is lung function irreversibly affected, and what is the histopathological response to diethylcarbamazine ?

A basic fact emerges from a study of all these biopsies. Clinically, what seems to be spasmodic bronchitis shows pathologically a gross involvement of the lung parenchyma and the bronchioles. Another fact is that the histiocyte may constitute the predominant cell-type in the lung picture.

An analysis of our sections enables us to suggest the evolution of the histopathological changes. The earliest pathological response of the 
lung is the out-pouring of histiocytes. This was noted in the three patients with typical clinical features in whom the biopsy was done within three weeks of the onset of symptoms. The fact that spasmodic nocturnal cough and breathlessness with diffuse wheezes occurred in all three patients, who did not have eosinophilic infiltration of the lung parenchyma, suggests that bronchospasm is not dependent on the type of cellular infiltrate in the lung but that it occurs as an independent response of the causative agent. It is significant that, in all these three 'early cases', though no acute eosinophilic lesions were present in the lung, the eosinophilic response of the marrow and the peripheral eosinophilia were quite definite.

'Acute eosinophilic abscesses' and 'eosinophilic bronchopneumonia' were found in those patients in whom the symptoms had been present for at least one month prior to the biopsy. We think that after the clinical infection there is a small interval during which time the lung tissue develops a hypersensitivity to the causative agent; the acute eosinophilic abscesses and eosinophilic bronchopneumonia are manifestations of such hypersensitivity. The severity, extent, and duration of this reaction will vary from one patient to another, depending on the general and local immunological state and also on the nature and dose of the exciting agent. Such hypersensitivity could also occur within a much shorter period after the onset of infection than is suggested by this study.

We have tried to explain the histiocytic infiltration in the lung in typical cases of tropical eosinophilia. At first sight it appears that the causative factor responsible for histiocytic infiltration is different from that which produces acute eosinophilic infiltration. But this is not very plausible, for in some sections eosinophilic lesions and histiocytic infiltration exist side by side. This finding suggests that the nature of the cellular response in the lung is determined more by variations in the 'soil' than in the 'seed'. Where the predominant cell type is the histiocyte it means that either local tissue (i.e., lung) hypersensitivity has not developed at all or it has died out after being present for a certain period. Cases showing typical 'mixed-cell type' of lesions suggest that tissue hypersensitivity is on the wane. Thus, as a general rule, the longer the duration of symptoms in a given case, the more frequently is either a 'mixed-cell type' or a chronic indolent histiocytic infiltration found. In any case, the histiocyte in tropical eosinophilia is no scavenger cell; nor does its presence necessarily denote resolution of the lesion. It is the result of an active tissue re- sponse to the causative agent in tropical eosinophilia.

That obvious pathological lung lesions can exist without any symptoms and signs in patients with high peripheral eosinophilia is proved by one patient in this series (Fig. 4). The amount of fibrosis in the lesion suggests that it had been there for a fair length of time, so that the slowly progressive pulmonary pathology must have failed to cause bronchial irritation and spasm and must in this case have been 'silent'.

It is noteworthy that this patient had a positive filarial complement fixation test and that the peripheral eosinophilia came to within normal limits after one month's course of diethylcarbamazine. However, all our work suggests that, though filarial infection is probably the commonest cause, other aetiological factors cannot be disregarded.

It is relevant to study the natural history of tropical eosinophilia left untreated for many years. There is little doubt that the longer the duration of symptoms the greater the pulmonary fibrosis. There was little emphysema in the cases studied, and the end result was usually a 'restrictive lung pathology'. Patient N. A. illustrates well the end result of a long-standing tropical eosinophilia. He presented with a history of paroxysmal nocturnal cough and breathlessness of 12 years' duration. He had a few wheezes and fine crepitations all over the chest; he was cyanosed and had obvious respiratory insufficiency with an arterial oxygen saturation of $70 \%$ but with no carbon dioxide retention. He had a total leucocyte count of $18,000 / \mathrm{c} . \mathrm{mm}$. with $90 \%$ eosinophils. The lung biopsy, however, showed a chronic indolent histiocytic lesion with much fibrous tissue formation, though we saw no eosinophils at all in the lung parenchyma. He was treated intensively with diethylcarbamazine and Carbarsone, and over a period of two months his leucocyte count fell to normal with normal eosinophils. Yet the symptoms and signs were unrelieved. It would have been impossible to distinguish clinically between this and asthmatic bronchitis, though the basic pathology was a chronic histiocytic and lymphocytic infiltration with much pulmonary fibrosis leading to respiratory insufficiency. His lung function tests suggested a restrictive pathology, the V.C. being $2,800 \mathrm{ml}$., and the F.E.V. $78 \%$ of his vital capacity.

We think there is a stage in the natural history of tropical eosinophilia when the lung hypersensitivity (i.e., eosinophilic infiltration in the lung) dies out and is replaced by a chronic indolent 
fibrotic lesion; the syndrome can still be recognized if the marrow hypersensitivity persists in the form of a peripheral eosinophilia. Sometimes the marrow hypersensitivity lessens or dies out altogether, either spontaneously or after specific therapy (as in patient N.A), but the pulmonary pathology remains and may even progress. The relationship of such cases to tropical eosinophilia may be difficult or impossible to trace, since they would present as pulmonary fibrosis or, as in the patient above (patient $\mathbf{N}$. A.), would be mistakenly diagnosed as asthmatic bronchitis.

Recent clinical and pathological observations (not included in this series) add further evidence that the disease need not be as benign as is generally thought, since the lung can be badly scarred and function adversely affected. Further proof is also forthcoming that sometimes the end result

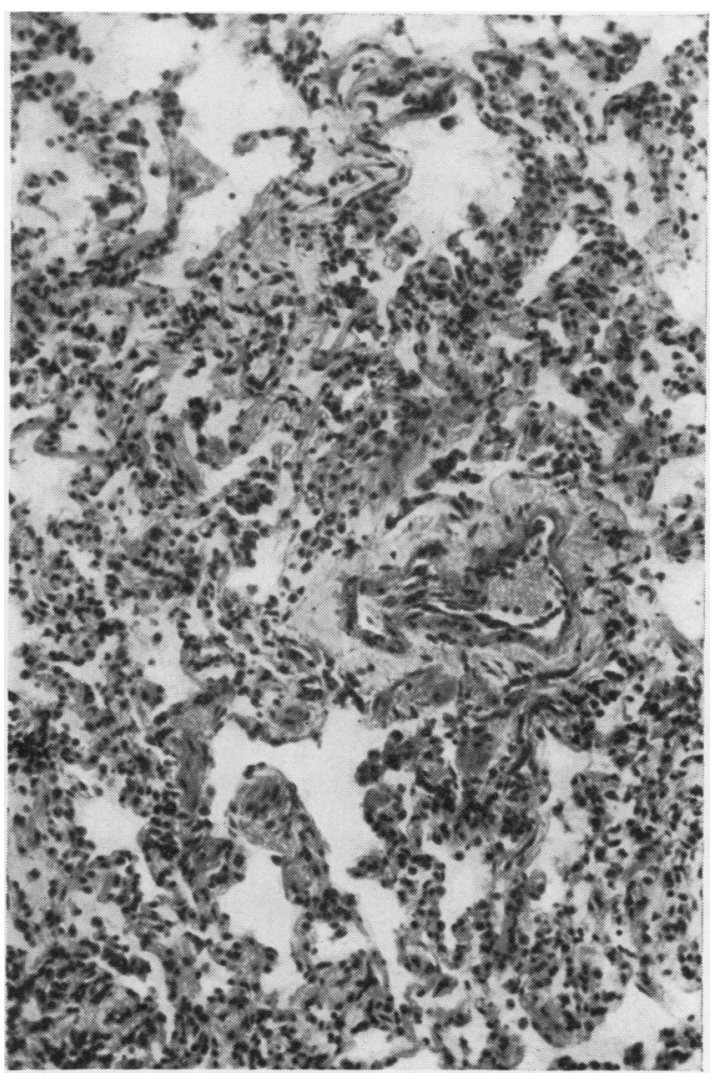

FIG. 8. Lung biopsy one month after diethylcarbamazine therapy. Extensive eosinophilic infiltration even though the patient was symptomless within seven days of therapy. $H$. and $E$., $\times 156$. may have very little resemblance to the typical syndrome as we recognize it at the beginning.

The response of the lung in tropical eosinophilia to specific therapy was studied in two patients who were given diethylcarbamazine for over a month before being submitted to biopsy. Both patients were completely free of symptoms after seven days' therapy, yet both patients had a gross pathology in the lung even after a month of treatment (Fig. 8). Three factors are worthy of note:

Relief of symptoms is not necessarily associated with a clearing of the lung pathology; both patients illustrate this point.

Lung pathology may exist in the absence of peripheral eosinophilia. Not only had all symptoms and signs disappeared but the peripheral eosinophilia had also returned to normal by the time the biopsy was done.

Histiocytes are not seen in areas where the eosinophilic exudate appears to be resolving.

Further study is necessary to decide whether the lung lesions can heal completely, or whether they may be scarred, and how long they take in these processes.

\section{SUMMARY}

Open lung biopsies were done on 26 patients with tropical eosinophilia. In 24 the biopsies were taken before starting specific therapy, and in two one month after specific therapy with diethylcarbamazine.

The three histopathological reactions were eosinophilic infiltration, histiocytic infiltration, and mixed-cell reactions where eosinophils and histiocytes occurred in almost equal proportions.

The longer the duration of symptoms the greater the pulmonary fibrosis. There was comparatively little or no emphysema, and an apparent spasmodic bronchitis might ultimately result in a 'restrictive lung pathology'.

A chronic indolent and slowly progressive fibrotic lung pathology could exist without any symptoms and signs which were not dependent on a cellular exudate, but were due to bronchial irritation and spasm arising independently from the causative agent.

Parasites were found in three out of 26 patients, and only in one were microfilaria definitely identifiable.

The two patients who had a biopsy after one month's treatment with diethylcarbamazine had incomplete histological regression, although they were free of symptoms within seven days of therapy. 
Tropical eosinophilia may not be as benign as is generally thought. The lung can be scarred, and sometimes lung function is adversely affected. Sometimes the tissue eosinophilia in the lung and the eosinophilia in the blood may die out without amelioration of symptoms because of chronic, persistent, and perhaps even progressive pulmonary changes. Such patients are difficult to recognize.

We wish to thank Dr. Virkar, the Dean, J. J. Hospital, for permission to use the hospital records for this paper. Our sincere thanks are given to Dr. W. Sulakhe for every encouragement in this work. We are deeply indebted to Prof. Gadgil, of the Pathology Department, for extending his unstinted co-operation and help in the histopathological study of the lung sections. Finally, our thanks to Mr. D. C.
Patel and Mr. M. P. Mehta for performing the open lung biopsies in our patients.

\section{REFERENCES}

Beaver, P. C., and Danaraj, T. J. (1958). Pulmonary ascariasi resembling eosinophilic lung. Amer. J. trop. Med. Hyg., 7, 100. C Chaudhut i, R. N. (1956A). Tropical eosinophilia. J. Indian med. Ass., 27, 195 . 27, 195 . Indian J. med. Res. 42,635 . and Saha, T. K. (1959). Tropical eosinophilia. Experiments with toxocara canis. Lancet, 2, 493.

- (1961). Tropical eosinophilia : an aetiopathological study. J. India med. Ass., 37, 317.

D'Abrera, V. St. E. (1958). The aetiology of 'tropical eosinophilia'. Cerlon med. J., 4 n.s., 195.

Gault, E. W. and Webb, J. K. G. (1957). Tropical eosinophilia. Hepatic lesions related to presence of nematode larvae. Lancet, $2,471$.

Viswanathan, R. (1947). Post-mortem appearances in tropical eosinophilia. Indian med. Gaz., 82, 49. (1948). Pulmonary eosinophilosis Ouart J. Med. 17, 257.

Webb, J. K. G., Job, C. K., and Gault, E. W. (1960). Tropical eosinophilia. Demonstration of microfilariae in lung. liver and lymphnodes. Lancet, 1, 835 . 